\title{
Evaluation of Filles Eveillees ("Girls Awakened"): A pilot program for migrant adolescent girls in domestic service
}

Sarah Engebretsen

Population Council

Follow this and additional works at: https://knowledgecommons.popcouncil.org/departments_sbsr-pgy

Part of the Demography, Population, and Ecology Commons, Family, Life Course, and Society Commons, Gender and Sexuality Commons, International Public Health Commons, Medicine and Health Commons, and the Migration Studies Commons How does access to this work benefit you? Let us know!

\section{Recommended Citation}

Engebretsen, Sarah. 2013. "Evaluation of Filles Eveillees ('Girls Awakened'): A pilot program for migrant adolescent girls in domestic service," evaluation report. New York: Population Council. 
EVALUATION OF

FILLES ÉVEILLEEES

(GIRLS AWAKENED):

A PILOT PROGRAM FOR

MIGRANT ADOLESCENT GIRLS IN DOMESTIC SERVICE

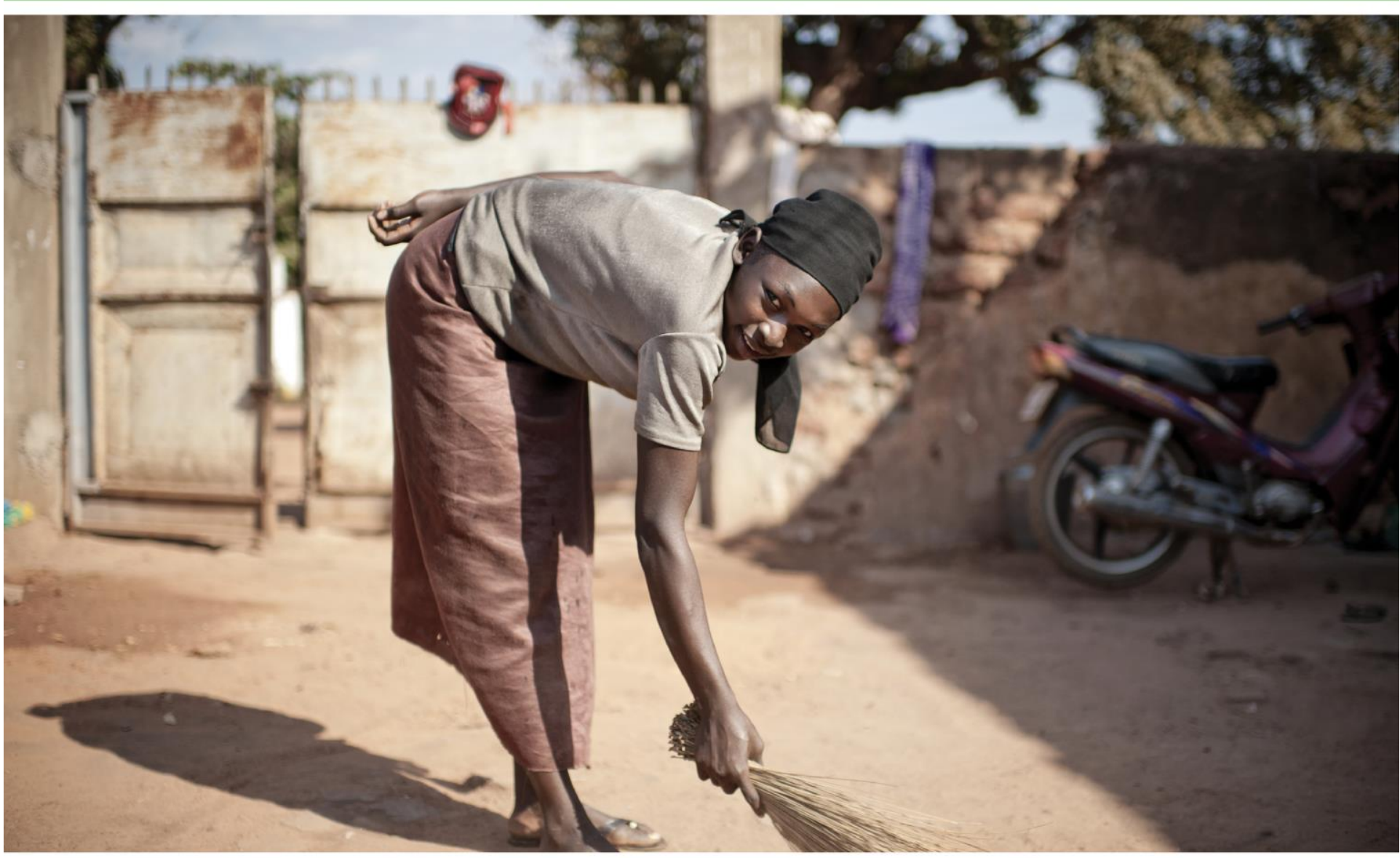

SARAH ENGEBRETSEN 


\section{(2) Population Council}

The Population Council confronts critical health and development issues-from stopping the spread of HIV to improving reproductive health and ensuring that young people lead full and productive lives. Through biomedical, social science, and public health research in 50 countries, we work with our partners to deliver solutions that lead to more effective policies, programs, and technologies that improve lives around the world. Established in 1952 and headquartered in New York, the Council is a nongovernmental, nonprofit organization governed by an international board of trustees.

Population Council

One Dag Hammarskjold Plaza

New York, NY 10017

www.popcouncil.org

Suggested citation: Engebretsen, Sarah. 2013. “Evaluation of Filles Éveillées (Girls Awakened): A pilot program for migrant adolescent girls in domestic service.” New York: Population Council.

Cover photo by Ollivier Girard, courtesy of the Population Council

(C) 2013 The Population Council, Inc. 


\section{INTRODUCTION}

Forty-six percent of the population of Burkina Faso falls below the age of 15 (PRB 2013), making its population one of the youngest in the world. Four out of five 1014-year-old rural females are out of school (Population Council 2009), and adolescent girls find few economic opportunities in Burkina Faso's rural areas. Disinvestment in rural adolescent females drives migration to urban areas in search of social and economic opportunities. The 2010 Burkina Faso Demographic and Health Survey showed that $25 \%$ of girls $10-17$ were not in school and not living with either parent. Many girls in this situation find employment in domestic service, which the ILO estimates is the largest occupation for girls under 16 worldwide (Temin et al. 2013). Living apart from families and working in an occupation that takes place behind closed doors, migrant domestic workers are at risk of sexual and economic exploitation. Furthermore, arduous work schedules leave little time for schooling, building social networks, and developing necessary skills for adulthood.

In response to this situation, the Population Council designed an intervention in urban Burkina Faso to increase migrant domestic workers' social capital; build their life skills as well as skills in health and hygiene, sexual and reproductive health, and financial capabilities with an option to re-enter school; and link them to services in their new surroundings. Known as Filles Éveillées (Girls Awakened), this intervention provides migrant adolescent girls in domestic service with a safe space to meet regularly, access to peers, and a female mentor. The intervention takes place over an eight-month period when migrant adolescent girls reportedly live and work in urban areas. ${ }^{1}$ Girls' groups meet once a week over a period of 30 weeks under the guidance of a female mentor. Additional information on intervention design, recruitment, mentor qualifications, and mentor training can be found in a brief on the program's first cohort (Engebretsen 2012).

The 2011-2013 pilot program reached 375 girls over two cycles: in 2011-2012 the intervention took place in Bobo Dioulasso (the second largest city in Burkina), and in

${ }^{1}$ Formative research conducted in 2010 revealed that girls' migration is seasonal and corresponds with the dry season as girls return home each year during the rainy season to help with agricultural tasks. Additional findings from the formative research can be found in Engebretsen (2012). 
2012-2013 the program was implemented in the capital city of Ouagadougou as well as Bobo Dioulasso. A pre- and post-test design was used to evaluate the Filles Éveillées program by assessing changes in participating girls' social capital as well as knowledge, attitudes, and behaviors in key program areas. Results from the first cohort are described elsewhere (Engebretsen 2012). This report adds to the program evaluation by measuring changes in girls participating in the second cohort from 2012-2013.

\section{METHODS}

This study was designed to explore the extent to which knowledge, attitudes, and behaviors evolved over the course of the eight-month intervention. The intervention and accompanying pre- and post-tests took place in three sectors in Bobo Dioulasso (Diaradougou, Koko, and Sarfalao) and five sectors in Ouagadougou (Kalgondin, Larlé, Silmissin, Tapouy, and 1200 logements). The pre-test was conducted in November 2012 before the program was implemented. The post-test was conducted shortly after program completion in late May/early June 2013. Migrant girls who fell within the target age range ${ }^{2}$ who were currently employed as domestic workers in one of the selected project sites were invited to participate in the program. Their employers or guardians were asked for permission. Both participants and employers were asked to sign the program permission form and consent to girls' participation in program surveys.

The survey, designed by Population Council researchers, was largely closed-ended and included sections on socio-demographic characteristics, life skills and social capital, health and hygiene, sexual and reproductive health, financial capabilities, and gender. Given the somewhat sensitive nature of survey topics, female interviewers administered the questionnaires, and questions were asked in the local languages (Dioula in Bobo Dioulasso and Mooré in Ouagadougou). Interviews were conducted in private away from employers and other household members to put the respondent at ease in answering questions. Interviews lasted between 45 minutes and one hour and were scheduled at a time most convenient for the girls. Interviewers were cognizant of domestic workers' busy schedules and scheduled interviews accordingly. A complete description of interviewer qualifications and training can be found elsewhere (Engebretsen 2012).

Data collection was supervised by a consultant with extensive experience conducting field research. The consultant also led the interviewer training, entered and cleaned

\footnotetext{
2 Formative research revealed that adolescent girls engage in step migration, or migration to a smaller city and then onto the capital city. The target age range therefore differs between Bobo Dioulasso (11-16) and Ouagadougou (15-19).
} 
the data, and worked with a Council researcher on the analysis. A field supervisor monitored data quality and questionnaire completeness. Data were analyzed using SPSS version 20.

Variables were created to measure constructs such as social capital, self-confidence, and gender equity. Additional variables were created to measure sexual and reproductive health knowledge: such as symptoms of pregnancy and STIs, modern methods of family planning, general HIV awareness, and self-protection against HIV. These summary measures are described below in the results section. This analysis comprises a comparison of means and percentages at baseline and endline for the overall sample and in the two sites. T-tests were computed in order to assess whether intended outcomes were significantly different between pre-test and post-test.

\section{RESULTS}

\section{Sample characteristics}

A total of 195 respondents completed the baseline survey, 123 in Ouagadougou and 72 in Bobo Dioulasso. The endline sample included a total of 140 girls, 96 in Ouagadougou and 44 in Bobo Dioulasso. This loss-to-follow-up is typical of programs reaching migrant populations, particularly in areas characterized by high rates of seasonal migration. Mean age at baseline was 15.5 with an expected higher mean reported in Ouagadougou than in Bobo Dioulasso. Half of the sample had ever attended school, with markedly higher rates in Ouagadougou than Bobo Dioulasso (63\% vs. $28 \%$ ). However, of those who had ever been to school, nearly two-thirds had not completed primary school.

The sample population was highly mobile, and employment was the most common reason given for migration. Almost half of all respondents reported living in their current neighborhood for less than one year. Nearly two-thirds of the respondents in Bobo Dioulasso reported living in their current area for less than one year, compared to one-third of respondents in Ouagadougou. This finding suggests step migration, where adolescent girls move first to a smaller city to gain skills before heading to the capital city. At baseline nearly three-quarters of the girls reported living with their employers. Although the majority of girls reported speaking the official language of the city where they lived, less than half of the baseline respondents spoke French and less than one-third were able to read in French as measured by a simple literacy test. At endline, two-thirds of respondents spoke French and nearly half were able to read in French. 


\section{Social capital and life skills}

Newly arrived migrant girls are at a double disadvantage in awareness of available resources and construction of social networks to help them access those resources (Temin et al. 2013). To combat this social isolation, Filles Éveillées provided girls opportunities to expand their social networks by participating in same sex groups led by adult female mentors. Social capital was assessed by measuring: participation in groups other than Filles Éveillées, having friends, having a place to meet friends, having a place to sleep in a time of need, having someone to borrow money from in an emergency, and having someone to turn to for advice. A range of 0-6 was possible on the social capital measurement, and the mean score significantly increased from baseline to endline as shown in Figure 1.

FIGURE 1: Mean social capital score among surveyed girls, by site and time of survey

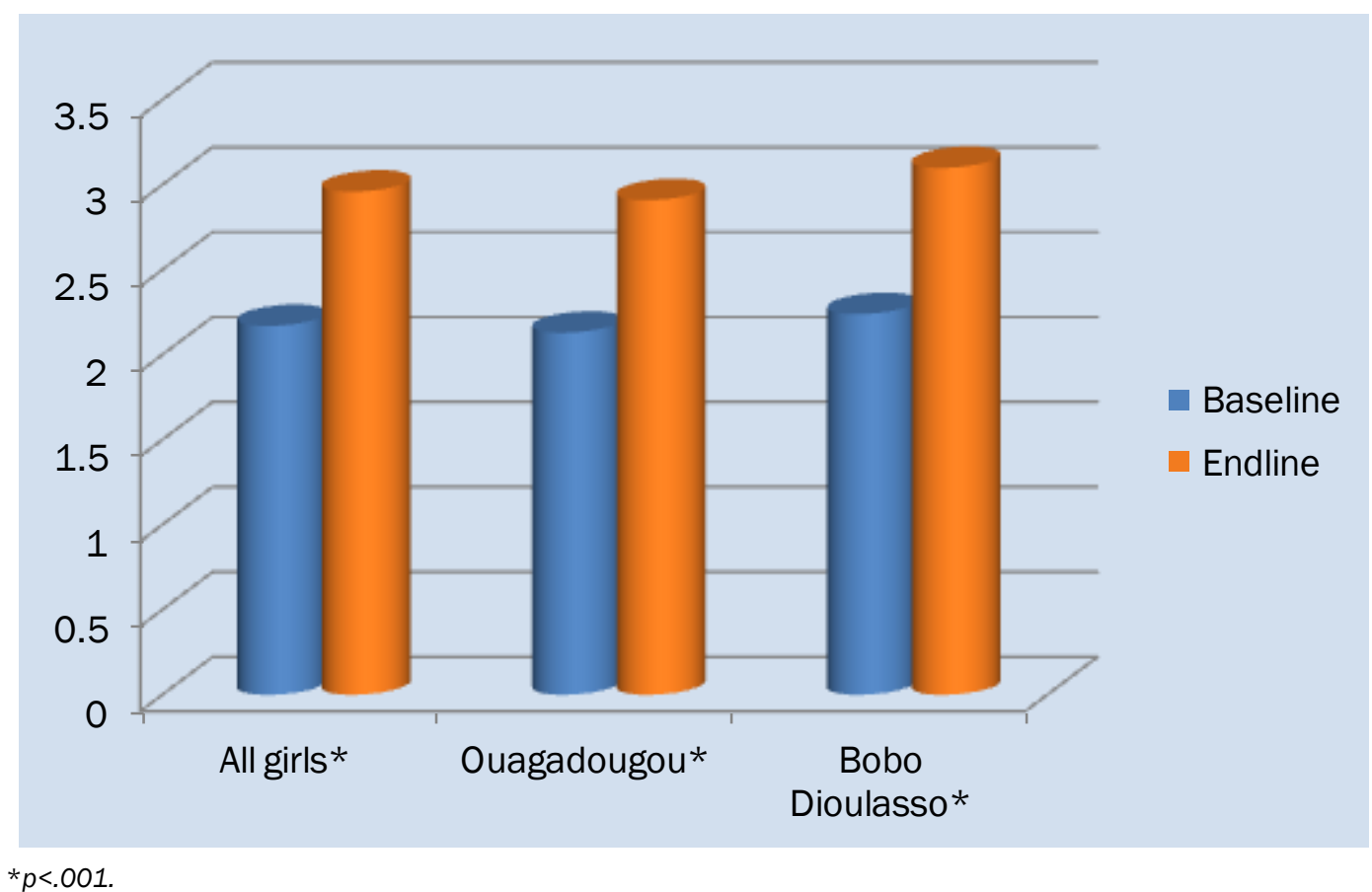

Significant differences were also found between baseline and endline on individual social capital variables: having friends ( $27 \%$ vs. $46 \%$ ), having a place to meet friends ( $21 \%$ vs. $66 \%$ ), and having someone to turn to for advice ( $81 \%$ vs. $93 \%$ ), all at $\mathrm{p}<.001$.

Filles Éveillées was designed to build self-confidence. The pre-test and post-test assessed a number of variables associated with girls' confidence including: high perceived power, not feeling timid in the presence of others, ability to make decisions for themselves, ability to resist peer pressure, satisfaction with educational 
attainment, hope for the future, not feeling weak or vulnerable, and ability to express themselves. With a range of $0-8$, mean level of self-confidence improved from baseline to endline from 4.08 to $4.46(p<.05)$. Significant differences were also found between baseline and endline on individual variables including not feeling timid (31\% vs. $44 \%, p<.05$ ), ability to make decisions for themselves ( $52 \%$ vs. $65 \%, p<.05)$, and not feeling weak or vulnerable (35\% vs. $47 \%, p<.05$ ). Significant differences were observed from baseline to endline in terms of percentage of girls reporting ability to resist peer pressure ( $88 \%$ vs. $76 \%, p<.01)$, though not in the expected direction.

\section{Health and hygiene}

The Filles Éveillées program provided participants with opportunities to learn about important topics related to health and hygiene. The program also provided girls with skills to manage their own health and explored attitudes around health-seeking behavior. Girls were asked what they did to manage their health when they were ill. Answers were grouped into the following categories: visiting a health center, selfmedicating, and using traditional remedies, and the first two are shown in Table 1.

TABLE 1: Percent of surveyed girls actively managing their health when ill, by site and time of survey

\begin{tabular}{|l|l|l|}
\hline Visiting a health center & Baseline \% (n) & Endline \% (n) \\
\hline Overall sample & $49 \%(195)$ & \\
\hline Ouagadougou & $43 \%(123)$ & $71 \%(140)^{*}$ \\
\hline Bobo Dioulasso & $60 \%(72)$ & $69 \%(96)^{*}$ \\
\hline Self-medicating & & $77 \%(44)^{* * *}$ \\
\hline Overall sample & $60 \%(195)$ & \\
\hline Ouagadougou & $65 \%(123)$ & $43 \%(140)^{* *}$ \\
\hline Bobo Dioulasso & $11 \%(72)$ & $44 \%(96)^{* *}$ \\
\hline
\end{tabular}

${ }^{*} p<.001 ; * * p<.01 ; * * * p<.05$

Respondents were asked why girls their age visit health centers. Multiple responses were possible, such as to obtain health information, contraception, and testing. Among the overall sample, a statistically significant increase was observed from baseline to endline in number of reasons why girls visit health centers (1.68 vs. 2.16 , $\mathrm{p}<.01$ ). This pattern held for both cities but was only significant in Bobo Dioulasso (1.03 vs. 1.66, $p$ <.01). Positive changes were observed in awareness of steps to be taken to improve one's health; at baseline, only 19\% knew that a girl their age could perform a breast self-exam compared to $65 \%$ at endline $(p<.001)$. This pattern was observed in both sites (22\% vs. $59 \%, p<.001$ in Ouagadougou; and $14 \%$ vs. $78 \%$, $\mathrm{p}<.001$ in Bobo Dioulasso). 
Girls' knowledge of hygiene was measured through questions about the circumstances under which it is appropriate for a person to wash his or her hands. Knowledge was much higher than expected, with $100 \%$ of the sample at baseline and endline reporting correct knowledge of circumstances requiring handwashing.

\section{Sexual and reproductive health}

In response to community concerns about migrant domestic workers' lack of sexual and reproductive health knowledge, the Filles Éveillées curriculum focused on providing girls with sexual and reproductive health education and information about services in their new surroundings. In the overall sample and in Ouagadougou, significant changes were observed in the percent of participants correctly identifying when during the menstrual cycle a woman can get pregnant ( $3 \%$ vs. $14 \%, p<.001$ ) and that missing one's period can be a sign of pregnancy ( $45 \%$ vs. $60 \%, p<.01$ ). However, observed differences in Bobo Dioulasso on these two items were not statistically significant.

Respondents were asked to name symptoms of pregnancy as well as symptoms of sexually transmitted infections. Summary measures were created to show mean knowledge of pregnancy and STI symptoms, and statistically significant differences were observed from baseline to endline on both indicators as shown in Table 2.

\section{TABLE 2: Mean knowledge of pregnancy and STI symptoms, by site and time of survey}

\begin{tabular}{|l|l|l|}
\hline & Baseline (n) & Endline (n) \\
\hline Pregnancy symptoms & & \\
\hline Overall & $1.43(195)$ & $2.53(140)^{\star}$ \\
\hline Ouagadougou & $1.70(123)$ & $2.74(96)^{\star}$ \\
\hline Bobo Dioulasso & $.96(72)$ & $2.07(44)^{\star}$ \\
\hline $\begin{array}{l}\text { STI symptoms } \\
\text { Overall }\end{array}$ & $.21(195)$ & \\
\hline Ouagadougou & $.28(123)$ & $1.51(140)^{\star}$ \\
\hline Bobo Dioulasso & $.08(72)$ & $1.75(96)^{\star}$ \\
\hline${ }^{*}<.001$ & & $.98(44)^{\star}$ \\
\hline
\end{tabular}

The analysis also assessed comprehensive awareness about modern contraceptive methods, using a summary index that summed correct responses to questions relating to in-depth awareness of methods such as oral contraceptive pills, injectables, IUDs, and condoms. This summary measure ranged from 0 to 9. Knowledge of modern family planning methods increased from baseline to endline. 
Girls' knowledge was significantly higher at endline in the overall sample (.75 to 1.46, $p<.001$ ), in Ouagadougou (.85 vs. 1.41, $p<.001$ ), and in Bobo Dioulasso (.58 vs.

$1.57, \mathrm{p}<.001)$.

Awareness of official places in the community providing family planning methods also improved over time, with $41 \%$ being able to name such places at baseline and $59 \%$ being able to do so at endline $(p<.001)$. This pattern held for both cities, though with statistical significance only in Ouagadougou ( $42 \%$ vs. $60 \%, p<.01)$. Over time, girls' knowledge of positive health behaviors during pregnancy-such as getting adequate rest, taking vitamins, and making regular prenatal visits-also improved. At baseline, mean knowledge of positive health behaviors during pregnancy among the whole sample was 1.14 , and at endline this increased to $2.46(p<.001)$. Statistically significant differences were observed across both sites.

General HIV knowledge was higher and attitudes toward testing were more positive than expected, with more than eight of 10 girls at baseline knowing that a healthylooking person can be infected with HIV and believing that girls their age should be tested for HIV. The analysis assessed comprehensive awareness about places in the community providing voluntary counseling and testing services, using a summary index that tallied correct responses to questions relating to in-depth awareness of places such as health centers or hospitals. This summary measure ranged from 0 to 5. Mean knowledge of places in the community providing testing services improved over time from 1.17 to 1.56 in the overall sample $(p<.001)$, and statistically significant differences were observed in both sites.

The analysis assessed awareness of methods of self-protection against HIV including abstinence, using condoms, and being faithful among others. The summary measure ranged from $0-5$, and the number of methods cited were grouped into low $(0-1)$, moderate (2-3), and high (4-5) knowledge. Awareness of self-protection against HIV improved over time as shown in Figure 2. However, at baseline more than one-fifth of girls believed that marriage protects against HIV, and this did not change significantly from the pre-test to the post-test. 


\section{FIGURE 2: Percent distribution of surveyed girls by awareness of methods to protect oneself against HIV, by site and time of survey}

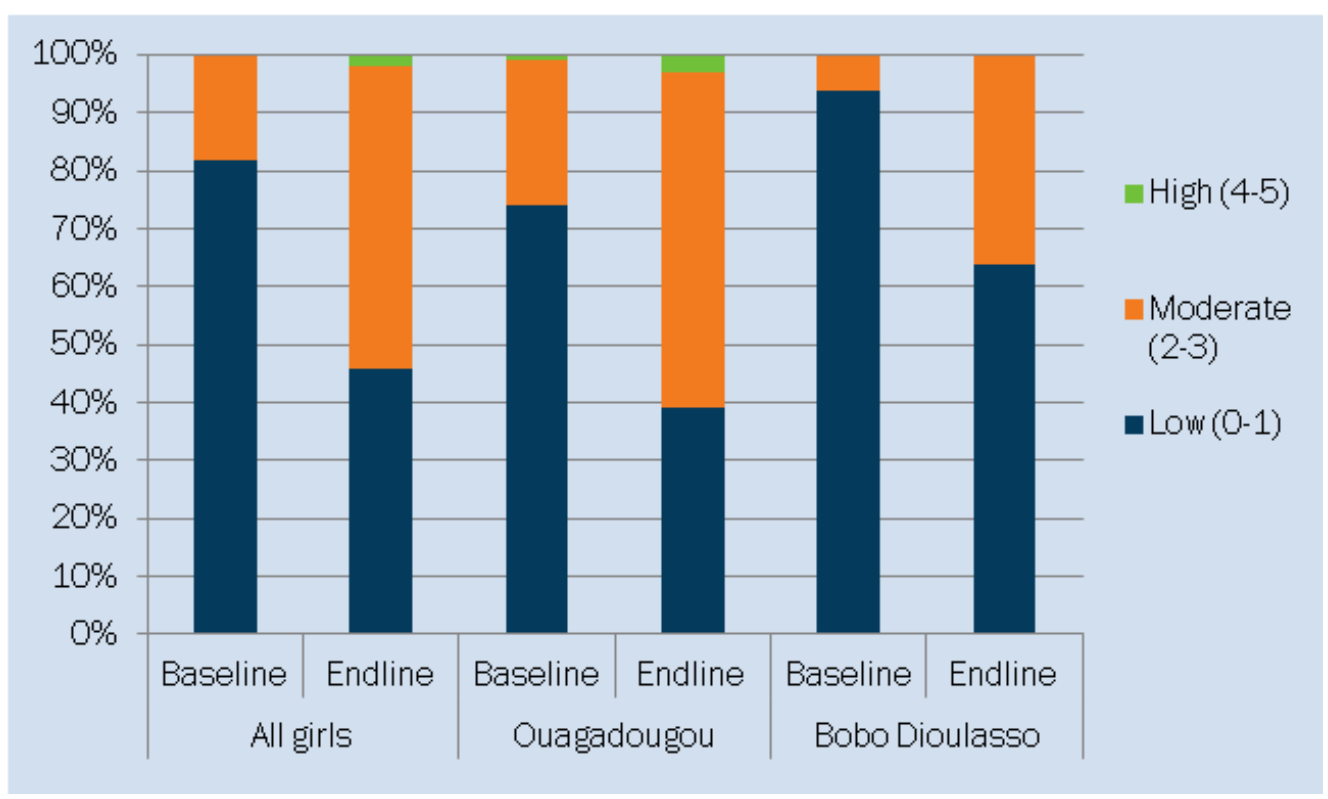

\section{Financial capabilities}

Given that girls in domestic service are already economically active, the program further developed their financial capabilities in savings, budgeting, planning for the future, and ability to talk about money. Girls had higher than expected numeracy levels, despite the fact that half of them had never been to school. At baseline $98 \%$ of girls correctly responded to an addition question. There was no statistically significant difference in this indicator between baseline and endline, likely owing to the high level observed at baseline.

Self-reported savings were higher than anticipated at baseline (74\%) and significantly improved by endline $(84 \%, p<.05)$. While only $2 \%$ of respondents reported saving in a bank at baseline, $9 \%$ reported doing so by endline $(p<.05)$. A statistically significant increase was also observed between baseline and endline in the proportion of girls informally saving (62\% vs. $76 \%$, p<.01). Girls reported both short-term and long-term reasons for saving, and statistically significant changes were observed from baseline to endline as shown in Figure 3. Short-term reasons for saving are defined as things the girl intends to do with her money in the next three months such as preparing for emergencies, personal shopping, purchasing clothes or utensils, or meeting other basic needs. Long-term reasons describe why a girl is saving for possible expenditures in the next year, such as paying for medical care, sending money to family, preparing for marriage, buying supplies for income-generating activities, or paying for professional training. 


\section{FIGURE 3: Percent distribution of surveyed girls having a short-term or long-term reason for saving, by time of survey}

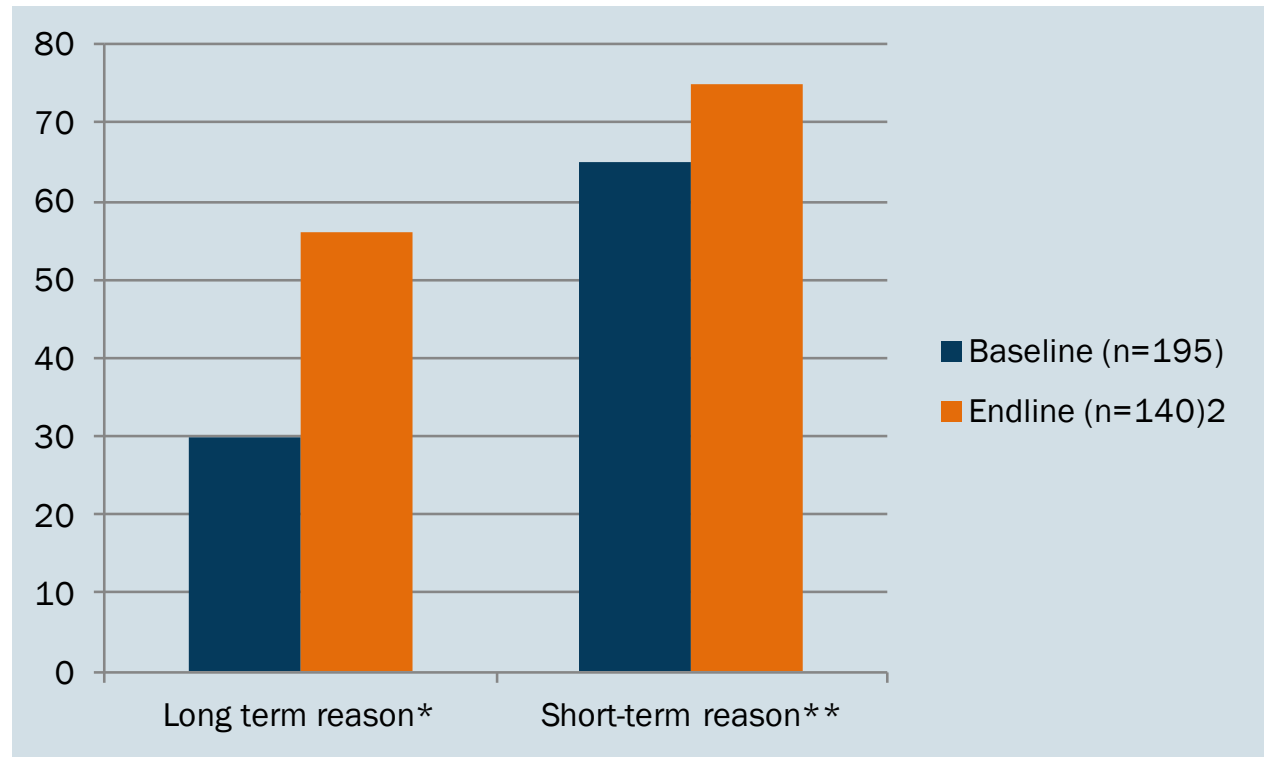

$* p<.001 ; * * * p<.05$

Girls' spending on investments in their future, such as education and training, increased over the period of the intervention. At baseline $11 \%$ of girls reported that they had spent money in the last year on their education, and this increased to $20 \%$ by endline. Recent spending on training increased from $5 \%$ at baseline to $9 \%$ at endline. A significant difference was observed from baseline to endline in the percent who reported having a savings plan (79\% vs. $88 \%, p<.05)$.

Girls were asked if they alone decide on how to spend their money or if others are involved in the decision. The percent of girls reporting that they alone decide on spending increased from baseline to endline ( $61 \%$ vs. $67 \%$ ). There was also an increase in the proportion of girls who reported being able to talk to employers about money ( $51 \%$ vs. $54 \%$ ). Neither of these differences, though, was statistically significant.

\section{Gender}

Filles Eveillées was not designed to change gender attitudes or gender norms. However, the pre-test and post-test assessed attitudes to see if participation in a girlonly, asset-building program had any effect on gender attitudes over time. In order to understand gender role attitudes, a total of six statements were read to adolescents and they were asked whether they agreed with the statements. For the first three statements-boys should spend as much time on house tasks as girls; women should 
be able to earn money; women should be able to marry who they want-agreement indicated gender equity. In contrast, for the last three statements-when parents do not have enough funding to send all children to school, boys' education should be prioritized over girls'; a woman should always obtain her husband's permission; and men have a right to beat their wives-disagreement indicated gender equity. Mean scores were computed to measure gender equity at baseline and endline. A statistically significant increase in gender equitable attitudes was observed in the overall sample over time, with a mean of 3.54 at baseline and 3.81 at endline. This pattern persisted for Ouagadougou (3.73 vs. 4.11) but not for Bobo Dioulasso.

\section{DISCUSSION}

The Filles Éveillées program was designed to increase social networks and skillbuilding among migrant adolescent girls in domestic service in urban Burkina Faso. The program was piloted over two cycles: 2011-2012 in Bobo Dioulasso, and 20122013 in Ouagadougou and Bobo Dioulasso. A process evaluation was conducted between the two cycles to assess program effectiveness and suggest improvements for program structure, implementation, and content before launching the second cohort. ${ }^{3}$ Changes resulting from this process evaluation included simplifying the SRH program content; reordering the modules and introducing financial capabilities earlier so that girls have ample opportunities to practice savings behavior; and reinforcing the importance of sessions that bring community service providers-such as nurses and financial service providers-to the girls to teach them about local resources. These course corrections likely enhanced the effectiveness of the Filles Éveillées program for the 2012-2013 cohort.

Findings from the pre-test and post-test with the second cohort showed measurable improvement at the level of the girl across all outcomes of interest. The findings demonstrated that despite the limited social networks of migrant adolescent girls in domestic service, it is possible to increase their social capital through regular meetings with same-sex peers under the guidance of a female mentor. This evaluation also showed that it is possible to alter girls' self-confidence and ability to manage their own health, and increase general health knowledge. Likewise, the Filles Éveillées evaluation shows that it is possible over time to change sexual and reproductive health knowledge-with particular attention to family planning, pregnancy, STIs, HIV, and resources available in the community. The second cohort also demonstrated that it is possible to change the savings and spending behaviors of migrant adolescent girls in domestic service.

\footnotetext{
${ }^{3}$ A complete description of the process evaluation can be found in Jarvis and Kaboré (2012).
} 
This study has limitations. First, the sample size is relatively small. However, migrant adolescent girls in domestic service are a numerous population in West Africa and elsewhere, and finding strategies to intervene on their behalf could be applicable in similar settings. Second, the lack of a control group means that changes observed from baseline to endline may not be attributable to the Filles Éveillées program. Nevertheless, the findings during the pilot phase were important in demonstrating the feasibility and acceptability of this program model and showing that girls' knowledge, attitudes, and behaviors can change over time. Future iterations of the program would benefit from a more rigorous research design. Third, the program was designed to coincide with the dry season when migrant girls live and work in urban areas. Data collection was accordingly scheduled to take place just before program implementation and just after program completion. However, a large number of girls returned to their villages before program completion. As a result, the post-test sample size was smaller than the pre-test, which introduces the possibility of selection bias.

Notwithstanding these limitations, the evaluation of the Filles Éveillées program demonstrates that it is possible to build skills among migrant adolescent girls in domestic service and link them to available services in their new communities. The program model provides important insights into how to build migrant girls' protective assets rather than just intervening after something has gone wrong. Advocacy efforts are needed to bring attention to isolated and vulnerable populations of migrant adolescent girls in domestic service, and implementation of new programs and research is needed to test innovative ways to prepare migrant girls for success (Temin et al. 2013).

\section{References}

Engebretsen, S. 2012. "Baseline and endline findings of Filles Éveillées ('Girls Awakened'): A pilot program for migrant adolescent girls in domestic service. Cohort 1 (20112012), Bobo-Dioulasso." New York: Population Council.

Jarvis, L. and Kaboré G. 2012. "Process evaluation: The Filles Éveillées (Girls Awakened) program for migrant adolescent girls in domestic service in urban Burkina Faso." Ouagadougou: Population Council.

Population Council. 2009. "The adolescent experience in-depth: Using data to identify and reach the most vulnerable young people: Burkina Faso 2003." New York.

Population Reference Bureau. 2013. World Population Data Sheet. Accessed October 9, 2013 http://www.prb.org/pdf13/2013-population-data-sheet_eng.pdf.

Temin, M., M.R Montgomery, S. Engebretsen, and K.M. Barker. 2013. Girls on the Move: Adolescent Girls and Migration in the Developing World. New York: Population Council. 